PSICOLOGIA, SAÚDE \& DOENÇAS, 2018, 19(1), 1-2

ISSN - 2182-8407

Sociedade Portuguesa de Psicologia da Saúde - SPPS - www.sp-ps.pt

DOI: http://dx.doi.org/10.15309/18psd190101

\title{
EDITORIAL
}

\section{PROMOVER E INOVAR EM PSICOLOGIA DA SAÚDE}

\section{Número da Revista dedicado ao $12^{\circ}$ Congresso Nacional de Psicologia da Saúde}

\author{
José Luis Pais Ribeiro ${ }^{1,2}$, Filipa Pimenta ${ }^{2} \&$ Alexandre Costa ${ }^{2}$ \\ ${ }^{1}$ Faculdade de Psicologia e de Ciências da Educação, Universidade do Porto; ISPA - Instituto Universitário; ${ }^{2}$ William James \\ Center for Research
}

O presente número especial da Revista Psicologia, Saúde \& Doenças visa a publicação dos melhores artigos desenvolvidos no contexto do $12^{\circ}$ Congresso Nacional de Psicologia da Saúde, evento que tem marcado a sua presença desde 1994, com o intuito de apresentação e divulgação da investigação nacional desenvolvida nesta especialidade e áreas afins.

Esta edição do evento bi-anual da Sociedade Portuguesa de Psicologia da Saúde, realizada entre os dias 25 e 27 de Janeiro de 2018 no ISPA - Instituto Universitário, com o apoio científico do William James Center for Research e da Ordem dos Psicólogos Portugueses, contou com mais de 400 comunicações que reforçaram a explanação do tema proposto para esta $12^{\mathrm{a}}$ edição, Promover e Inovar em Psicologia da Saúde.

A atualidade impõe desafios à sociedade (e aos psicólogos que trabalham na área da Psicologia da Saúde), e a sua gestão pede uma resposta não só adequada, como também inovadora, considerando a emergência de problemáticas ou a crescente incidência. A exacerbação dos fluxos migratórios, a violência e a marginalização, a elevada prevalência de doenças crónicas não transmissíveis tendo por base factores de risco (comportamentais) modificáveis, a dependência da internet, o envelhecimento da população mundial, as alterações climáticas, a crescente dificuldade dos serviços de saúde em darem resposta a necessidades específicas, e deterioração das condições laborais, impõem aos Psicólogos da Saúde, tal como à sociedade em geral, a avaliação de impactos e geração de soluções num diálogo multidisciplinar. Apesar dos desafios, detectam-se igualmente oportunidades para inovar a forma como intervimos na doença e promovemos saúde, trabalhamos as redes disponíveis, e integramos a ciência e a prática orientada para as necessidades do utente/cliente. Neste contexto, realizou-se com sucesso o $12^{\circ} \mathrm{CNPS}$ que, na nossa opinião, permitiu refletir sobre o papel do/as Psicólogo/as da Saúde como agentes de promoção de saúde e inovação na sua entrega, junto de populações diversas.

Foi com muita satisfação que acolhemos a contribuição científica para este evento de colegas de todo o país, assim como de Espanha, Itália e Brasil.

A investigação apresentada focou áreas emergentes como avaliação e intervenção com recursos a novas tecnologias, dependência da internet, psicologia ecológica; populações específicas (migrantes, minorias sexuais, idosos); e de âmbito mais lato, como a humanização dos serviços de saúde, bem-estar na sociedade e emprego, e violência e justiça. Este número especial da Psicologia, Saúde \& Doenças consiste na contribuição dos artigos candidatos a prémio ou recomendados pela Comissão Científica para publicação no número especial por se distinguirem pela qualidade do seu contributo. Assim, ocupam lugar de destaque trabalhos de validação psicométrica, fenómenos clínicos (percepção de dor, alexitimia, esclerose lateral amiotrófica, cirurgia bariátrica), 


\section{PROMOVER E INOVAR EM PSICOLOGIA DA SAÚDE}

comportamentos de saúde (à realização do teste de VIH, literacia alimentar e em saúde, meditação) e de doença (utilização problemática da internet), e sexualidade. As populações focadas incluem crianças, jovens adultos, meia-idade (menopausa e andropausa), idosos e minorias (comunidade hindu, LGBT). Contextos particulares (familiar, escolar, institucional) e papéis específicos (relação de supervisão; parentalidade; desempenho social de jovens) foram igualmente explorados na sua relação com a saúde.

Endereçamos um sincero agradecimento a todos os membros da Comissão Científica, da Comissão Organizadora e a todos os Participantes, assim como ao ISPA-Instituto Universitário e William James Center for Research, cuja participação e apoio tornaram possível o sucesso de mais uma edição do Congresso Nacional de Psicologia da Saúde.

É nossa opinião que os artigos que se seguem exemplificam a pluralidade e qualidade dos investigadores nacionais (e internacionais) na área da Psicologia da Saúde, desejando a todos os Leitores uma óptima leitura dos contribuições científicas que se seguem. 